\title{
The conflicts between professional and non-professional work of community pharmacists in Indonesia
}

\author{
Andi HERMANSYAH, Anila I. SUKORINI, Catur D. SETIAWAN, Yuni PRIYANDANI. \\ Received (first version): 12-Aug-2011 Accepted: 22-Feb-2012
}

\begin{abstract}
${ }^{*}$
Objectives: The study aimed to determine the type of professional and non professional work of community pharmacists in Surabaya Indonesia and find the difference between time spent for performing both works in actual (current) situation and ideal (expected) situation.

Methods: A cross sectional study was conducted by combining purposive sampling for selecting the community pharmacists. Afterwards, the data was analyzed using SPSS v16 to provide the descriptive results and completed with Wilcoxon signed rank test to find the difference between time spent in actual and ideal situation. The sample size was 100 respondents of 300 pharmacists who have been practicing in Surabaya.
\end{abstract}

Results: From 100 participants just 30 participants gave response to the questionnaire, $67 \%$ was female who $20-30$ years old at most $(53 \%)$ with working experience as pharmacist less than 3 years $(60 \%)$ and working 30 hours per week $(60 \%)$ in pharmacy. Significant difference between time spent in actual and ideal situation was found. Discussion: The time spent for performing professional and non professional work in ideal situation was significantly higher than in actual situation except for preparing medicines activity. This finding illustrated that the respondents did not have adequate time to provide ideal services in their daily practice. Therefore, they expected to improve their time and level of work in more professional manner. Surprisingly, they were also willing to provide more time and higher level of work in some non professional work.

Conclusions: The Indonesian community pharmacists spent little time on both professional work and non-professional work in their daily activities. This indicated that the pharmacists did not focus on delivering quality professional work.

Keywords: Community Pharmacy Services. Pharmacists. Workload. Professional Practice. Indonesia.

*Andi HERMANSYAH. M.Sc. Community Pharmacy Department, Faculty of Pharmacy, Airlangga University. Surabaya, East Java (Indonesia).

Anila I. SUKORINI. B.Pharm., Community Pharmacy

Department, Faculty of Pharmacy Airlangga University. Surabaya, East Java (Indonesia).

Catur D. SETIAWAN. B.Pharm. Community. Pharmacy Department, Faculty of Pharmacy, Airlangga University. Surabaya, East Java (Indonesia).

Yuni PRIYANDANI. Sp.FRS. Community Pharmacy

Department, Faculty of Pharmacy, Airlangga University.

Surabaya, East Java (Indonesia).

\author{
CONFLICTOS ENTRE EL TRABAJO \\ PROFESIONAL Y NO PROFESIONAL DE \\ LOS FARMACÉUTICOS COMUNITARIOS \\ EN INDONESIA
}

\section{RESUMEN}

Objetivos: El estudio trató de determinar el tipo de trabajos profesionales y no profesionales de los farmacéuticos comunitarios en Surabaya, Indonesia, y encontrar las diferencias entre el tiempo dedicado a realizar ambos tipos de trabajo en la situación real (actual) e ideal (esperada). Métodos: Se realizó un estudio transversal combinando muestras propositadas de farmacéuticos comunitarios seleccionados. Después, se analizaron los datos usando SPSS v16 para proporcionar los resultados descriptivos y se completaron con un test de los signos de Wilcoxon para encontrar la diferencias entre los tiempos en la situación real e ideal. El tamaño de muestra fue de 100 respondentes de los 300 farmacéuticos que estaban en ejercicio en Surabaya.

Resultados: De los 100 participantes, solo 30 dieron respuesta al cuestionario, siendo el $67 \%$ mujeres, con 20-30 años de edad (53\%), con una experiencia como farmacéuticos de menos de 3 años $(60 \%)$ y trabajando 30 horas por semana $(60 \%)$. Apareció diferencia significativa entre los tiempos en la situación real e ideal. El tiempo dedicado a realizar trabajos profesionales y no profesionales en la situación ideal era significativamente mayor que en la situación real, excepto para la actividad de preparar medicamentos. Este resultado ilustró que los respondentes no tienen suficiente tiempo para proporcionar los servicios ideales en su práctica diaria. Por tanto, esperan mejorar su tiempo y nivel de trabajo de un modo más profesional. Sorprendentemente, deseaban dedicar más tiempo y subir el nivel de trabajo en algunos trabajos no profesionales.

Conclusión: Los farmacéuticos comunitarios indonesios pasan poco tiempo, tanto en trabajos profesionales como no profesionales en sus actividades diarias. Esto indica que los farmacéuticos no se centran en realizar trabajo de calidad profesional.

Palabras clave: Servicios de Farmacia Comunitaria. Farmacéuticos. Carga de Trabajo. Práctica Profesional. Indonesia. 


\section{INTRODUCTION}

Pharmacists are known as professionals in healthcare, specifically in pharmaceuticals. ${ }^{1,2}$ The current trend of pharmaceutical care has shifted traditional role of pharmacist from dispenser of drugs towards a consultant of medication. Nowadays, Pharmacists are responsible to help the patients by maintaining their health and promote the use of rational medicines to improve the patients' quality of life. This newest role has reconstructed the professional image of pharmacist. ${ }^{3}$

Based on definition, a professional should have one of distinguishing features of a professional group. ${ }^{4}$ These features may include monopoly over the profession to perform the professional practice. ${ }^{5}$ In other words, as a professional, pharmacists possess the authority to professionally work in pharmacy thus their primary responsibility is delivering a professional work for their user, e.g. patients. However, the case might be different for community pharmacists where the professional side is sometimes conflicted with the commercial side.

Based on the Pharmacy Practice Activity Classification (PPAC) initiated by American Pharmacists Association ${ }^{6}$, Community Pharmacist covers wide range of works from (1) ensuring appropriate therapy and outcomes, (2) dispensing medication and devices, (3) doing health promotion and disease prevention, up to (4) giving contribution to health systems management. These are the professional work standard for community pharmacists. Unfortunately, the existence of pharmaceutical products as a commodity has conflicted the professional works of pharmacists.

It is no longer a secret that community pharmacists are usually overburdened with the supply and demand of medicines. In addition, what a community pharmacist does in everyday practice sometimes cannot be determined whether it is job of professional that characterizes professional feature or it is job of a nonprofessional that focuses on medicine as a commodity. A study by Cordina $^{7}$ showed that community pharmacist were more comfortable and competent to involve in managerial and dispensing activities rather than investing their time to pharmaceutical care practice such as interacting with physicians and patients or engaging in professional activities. Therefore, before Cordina presented her research, Denzin and Mettlin in 1968 had started to call community pharmacy as "incomplete profession" because their professional role was overruled by elements of nonprofessional work. $^{8}$

Studies by several authors ${ }^{9,10}$ indicated that pharmacists in the community act double role as professional pharmacist who perform pharmaceutical care and businessman whose jobs are merely focusing on profit gain. As businessman or retailer, pharmacist does works that are not correlated with the profession. These activities may vary from staffing, housekeeping or selling items which are not directly related to the profession for instance items often seen in the stalls or grocery store. Thus, these types of work are classified as commercial side of community pharmacist.

The friction of commercial side caused the fade away of the pharmacist's professionalism and creates the state of de-professionalization. ${ }^{11-14}$ As the consequence, professional service may not longer be valued as the main output of the profession, except the product. Another consequence is the lost of monopoly which threats the profession and currently happened in some countries. $^{15-17}$

In Indonesia, community pharmacy practice is regulated by three main regulations which are National Health Law 2009, Pharmacy Practice Law 2009 and Standard of Community Pharmacy Service 2004. The first two regulations state that pharmacist is a professional healthcare provider who is the most responsible person in the community pharmacy, thus he or she has to assure that services delivered are beneficial to the users. According to these rules, there are two groups of pharmacy workforce which are allowed to work in the community pharmacy. Those are pharmacist and pharmacy technician. The technician supports the pharmacist daily work particularly for preparing and compounding the medicine. The last regulation comprehensively explains the standard of practice that a community pharmacist has to achieve when delivering pharmacy services. This standard covers wide range of topics from premises, the human resources up to pharmaceutical care issues. The initial step before delivering pharmacy services according to this regulation is screening the drug request either from prescription or self-medication. Preparing and dispensing the medicines are the next steps and it is ended with the counseling and monitoring of the therapy.

Based on the assumption of professional and non professional side of community pharmacist, a study was conducted to obtain information about the type of professional work (based on PPAC) and the non professional work performed by community pharmacists in Surabaya Indonesia. To determine the de-professionalization state, this study calculated the difference between time spent to perform the professional and non professional work in actual situation (the situation in which they currently do) and ideal situation (the situation in which they expect to do).

Surabaya as the area of research is the second biggest city and the second most populous city in Indonesia. It has been inhabited by almost 3 million people in 2008 with approximate population density was 8.7 thousand people/ $/ \mathrm{Km}^{2}$. The age of $20-45$ years dominated the Surabaya's population pyramid with almost $50 \%$ of the total population. The healthcare access is provided by 102 public healthcare facilities ranging from primary care services to modern hospitals. Private hospitals and clinics are also established to improve the healthcare level. In general, as a metropolitan city, standard of living and standard of health care are noticeably sufficient to support the dynamic of its citizen. $^{18}$ 


\section{METHODS}

Study design: A descriptive, cross sectional study design was chosen as the means to investigate the type of professional and non professional work amongst community pharmacists in Surabaya. Data were collected using questionnaire by visiting the selected pharmacies.

Sampling methods: There were 300 pharmacies in Surabaya. A sample of 100 respondents was randomly selected using specific sample size equation with confidence level $95 \%$ and confidence interval $10 \%$,

$$
s s=\frac{Z^{2} *(p) *(1-p)}{C^{2}}
$$

The respondents were selected by lottery method using sampling frame of the registered pharmacist in Surabaya. Those who were not available or unable to be assessed by the surveyor would be rejected and automatically substituted by other new respondents. Each surveyor had to meet the respondents to assure that they had filled out the questionnaire correctly. The study was conducted from April to June in 2010.

Data collection: A questionnaire covered questions on demographic information and several types of pharmacist's work include professional and non professional work. The subject of the question in this section was mainly developed from Pharmacist Practice Activity Classification (PPAC) created by American Pharmacist Association (APhA). Some modifications were created to adapt with local situation in Surabaya. The results were seven features of professional work and three features of non professional work. The features of professional work were: (1) ensuring prescription appropriateness; (2) preparing the medicine; (3) dispensing the medicine; (4) doing health promotion; (5) managing the health system in pharmacy; (6) counseling for OTC (Over the Counter) drugs; and (7) other professional activities (e.g. professional training, forum with other healthcare professional). While the features of non professional work were: (1) staffing (e.g. recruitment, staff positioning, scheduling, staff training); (2) housekeeping (e.g. cleaning and merchandising the pharmacy); and (3) other non professional activities (e.g. selling non medicinal products such as soap, shampoo, snacks and beverages). The respondents were asked to rate the time spent in the actual situation and the time spent that they ideally wanted to do. Rate 1 means least of the time spent in such activity while rate 5 means most of the time spent. Written consent was obtained from the respondents as an agreement for participating in the survey.

Before the survey started, four experts acted as a panel to review the content and the layout of the questionnaire. The experts were the representatives of local pharmacist association. They were asked to validate whether the questionnaire was acceptable or not for the pharmacist. An approval was obtained from the local pharmacist association as a legal basis to conduct the survey.
Data analysis: Data were entered into SPSS (Statistical Package for Social Service) version 16 while descriptive analysis was provided in frequencies only. Apart from this, appropriate non parametric statistical test were utilized to establish the difference between variables. Wilcoxon signed rank test was used for significant difference between times spent for performing professional and non professional work in actual and ideal situation. The statistical significance level (alpha) was 0.05 with confidence interval of $95 \%$.

\section{RESULTS}

Whole 30 respondents of survey which completed the questionnaire were giving a response rate of $30 \%$. The details of demographic data of respondents were provided in table 1.

Using the mean of the respondents' rate which varied from 1 (least time spent in the selected activity) to 5 (most of the time spent in the selected activity), the study found that there was significant difference $(p<0.05)$ between time spent by the community pharmacists in the actual and ideal situation in both delivering the professional and non professional work where time spent in ideal situation was significantly higher than time spent in actual situation for all activities, except for preparing the medicines where there were no difference between time spent in actual and ideal situation (Table 2).

\begin{tabular}{|c|c|}
\hline Variables & Responses (\%) \\
\hline \multicolumn{2}{|l|}{ Age (year) } \\
\hline $20-30$ & 53 \\
\hline $31-40$ & 33 \\
\hline $41-50$ & 7 \\
\hline$>51$ & 7 \\
\hline \multicolumn{2}{|l|}{ Gender } \\
\hline Male & 33 \\
\hline Female & 67 \\
\hline \multicolumn{2}{|l|}{$\begin{array}{l}\text { Working experience as community } \\
\text { pharmacist (year) }\end{array}$} \\
\hline & 17 \\
\hline $1-3$ & 43 \\
\hline $4-0$ & 23 \\
\hline $11-20$ & 10 \\
\hline$>20$ & 7 \\
\hline \multicolumn{2}{|l|}{$\begin{array}{l}\text { Working experience in the current } \\
\text { pharmacy (year) }\end{array}$} \\
\hline Priamady (year) & 27 \\
\hline $1-3$ & 50 \\
\hline $4-0$ & 13 \\
\hline $11-20$ & 7 \\
\hline$>20$ & 3 \\
\hline \multicolumn{2}{|l|}{ Current position } \\
\hline Self employed & 17 \\
\hline Mid career & 7 \\
\hline Junior level & 28 \\
\hline Senior employee & 48 \\
\hline \multicolumn{2}{|l|}{ Working hours per week } \\
\hline$<10$ & 30 \\
\hline $11-20$ & 13 \\
\hline $21-30$ & 17 \\
\hline $31-40$ & 13 \\
\hline$>40$ & 27 \\
\hline $\begin{array}{l}\text { The number of pharmacist in the } \\
\text { pharmacy [mean (SD)] }\end{array}$ & $1.77(1.04)$ \\
\hline $\begin{array}{l}\text { The number of technician in the } \\
\text { pharmacy [mean (SD)] }\end{array}$ & $3.93(5.13)$ \\
\hline
\end{tabular}




\begin{tabular}{|c|c|c|c|c|}
\hline \multirow{2}{*}{ Variable } & \multirow{2}{*}{$p$-value } & \multicolumn{3}{|c|}{ mean (SD) } \\
\hline & & Actual & Ideal & Gap \\
\hline $\begin{array}{l}\text { Ensuring prescription appropriateness (e.g. ensuring the legal aspect of the } \\
\text { prescription, ensuring the patient's status and patient's understanding) }\end{array}$ & $<0.001^{+}$ & $3.24(1.12)$ & $4.52(0.91)$ & 1.28 \\
\hline $\begin{array}{l}\text { Preparing the medicines (e.g. selecting the appropriate medicines and } \\
\text { devices, processing prescription) }\end{array}$ & 0.068 & $3.10(1.20)$ & $3.55(1.15)$ & 0.45 \\
\hline $\begin{array}{l}\text { Dispensing the medicines (e.g. reviewing The prescription, delivering } \\
\text { medication or health devices, monitoring and reporting outcomes) }\end{array}$ & $0.001^{+}$ & $3.26(1.22)$ & $4.26(1.05)$ & 1 \\
\hline $\begin{array}{l}\text { Doing Health promotion (e.g. Delivering preventive services, surveillance } \\
\text { and reporting public health issue, promoting safe medication use) }\end{array}$ & $<0.001^{+}$ & $2.17(1.07)$ & $3.82(1.21)$ & 1.65 \\
\hline $\begin{array}{l}\text { Managing the health system in the pharmacy (e.g. managing the practice, } \\
\text { encouraging medication therapy management, participating in the health } \\
\text { system management by facilitating documentation of pharmaceutical care or } \\
\text { developing quality assurance system in the practices) }\end{array}$ & $0.001^{+}$ & $3.10(1.11)$ & $3.93(1.04)$ & 0.83 \\
\hline $\begin{array}{l}\text { Counseling for OTC (e.g. ensuring the patient's condition for self medication } \\
\text { purposes, assisting patient to select the appropriate OTC drug, giving } \\
\text { information related to the OTC selected by patients) }\end{array}$ & $<0.001^{+}$ & $3.34(1.23)$ & $4.36(1.02)$ & 1.02 \\
\hline $\begin{array}{l}\text { Other professional activities (e.g. Professional training, forum with other } \\
\text { healthcare professionals, engaging in (Interdisciplinary collaboration) }\end{array}$ & $<0.001^{+}$ & $2.29(1.11)$ & $3.90(0.94)$ & 1.61 \\
\hline $\begin{array}{l}\text { Staffing (e.g. recruiting staff, allocating staff schedule, determining fees and } \\
\text { income or another routine "back office" management) }{ }^{*}\end{array}$ & $0.001^{+}$ & $2.24(1.18)$ & $3.23(1.25)$ & 0.99 \\
\hline $\begin{array}{l}\text { Housekeeping (e.g. merchandising item, lay outing the promotional material, } \\
\text { daily cleaning the pharmacy) }\end{array}$ & $0.017^{+}$ & $2.07(1.03)$ & $2.57(1.23)$ & 0.5 \\
\hline $\begin{array}{l}\text { Other nonprofessional activities (e.g. selling non medicinal products such as } \\
\text { soap, shampoo, snacks and beverages) }{ }^{*}\end{array}$ & $0.031^{+}$ & $2.20(1.15)$ & $2.72(1.22)$ & 0.52 \\
\hline \multicolumn{5}{|c|}{$\begin{array}{l}\text { The rate of } 1 \text { to } 5 \text { is the tendency of the respondents to spend their time on the chosen variable where } 1 \text { means least time spent } \\
\text { while } 5 \text { means most of their working time spent in selected activity. } \\
\text { To make a clear distinction between each variable, surveyors were equipped with the definition of each variable. A surveyor had } \\
\text { to explain the definition to the respondents before collecting the answers. Some examples were provided to make each variable } \\
\text { clearer. } \\
\text { variable of non-professional work } \\
+ \\
\text { significant if } p<0.05\end{array}$} \\
\hline
\end{tabular}

There were gaps between professional work in ideal and actual situations that indicated a significant willingness of community pharmacist to change their current practice into an ideal situation that required more involvement of the pharmacist. Most of the gaps in the professional work dramatically increased over than 0.8 point different, except for activities in preparing medicines.

On the other hand, the different patterns were found in non professional work. Although, there were increases on the number of time required by the pharmacists to deliver non professional work in ideal situation, the overall gaps were not as high as the gaps in professional work. The maximum gap was only 0.9 point different. It showed that pharmacists would not be willing to dramatically change their current practice and tend to deliver non professional works in a regular way.

\section{DISCUSSION}

There is always question on how to measure professionalism of a profession. Many experts said that professionalism is hardly measured. Rutter and Duncan ${ }^{19}$ stated that professionalism is a complex terminology that composed of structural, attitudinal and behavioral attributes that is clearly difficult to measure. None of studies they reviewed were able to ensure the effectiveness of the tools to measure professionalism. In case of pharmacist, Dingwall and Wilson ${ }^{20}$ said that there is no consensus on defining the basic characters of professions and professionalism. However, there is commonsense that a professional is required to deliver a professional work because of their knowledge superiority. This sense is also applied for community pharmacists who publicly recognized as professional in pharmaceuticals. Therefore, to deliver professional works is a like an obligation for community pharmacist.

This paper found that Indonesian community pharmacists were spending little time for all activities both for professional and nonprofessional work in actual situation, except for activity on preparing the medicines where there were no differences between times spent in both situations. Therefore, in ideal situation, the respondents would like to devote more of their time to provide all activities which has not been afforded a full opportunity to engage in the actual situation.

The result showed that Indonesian pharmacists were not committed to provide professional works of pharmacist such as required by the PPAC. From seven professional work variables listed, just preparing the medicines that they claimed adequate to be provided in actual and ideal situation, while the other variables were not sufficiently provided in the actual situation. On average, there was also 1 point gap where the times spent to provide the works in ideal situation was higher than in actual situation. This indicated that the respondents were desired to provide more time delivering the work particularly on the variables of health promotion and providing other professional activities where the gap was the highest amongst others.

This finding is similar to study of Smith ${ }^{21}$ which explained that community pharmacists in developing countries are still focused on medicine as the output of the pharmacy services. As a result, the quality of pharmacy service is lacking, questionable and often unclear. Finding in table 1 
supported this argument where the data showed that majority of the respondents only worked less than 20 hours per week which means availability of pharmacist was still a major problem for providing professional services. This finding also means that the respondents were having poor time to interact with the patient. The small amount of time to interact with the patient supported the evidence that the pharmacist was hardly trying to be a professional. Their availability in the pharmacy was no longer important for patient as long as they got the products. Patients come to pharmacy just to get their drugs and not getting service from pharmacists.

This concord with the findings in Ghana where community pharmacists would actually potential to contribute more to health care in communities if they were available during pharmacy operates. ${ }^{22}$ This availability is important to ensure the high quality services. Many researchers have demonstrated that an accessible pharmacist may response to consumer needs and perspectives better. Therefore, it is not surprising that the result of this research showed that pharmacists were willing to improve their time on doing professional work in the ideal situation. By increasing time on professional work, pharmacist would have more attention to community issues and they would be acknowledged better by the societies.

Interestingly, the Indonesian community pharmacists were not only desired to level up their time in providing professional work but also for providing non professional work which are not part of the pharmacist duty. Although the gaps are not as high as in professional work variables, the result indicated that there was blurred job description between the pharmacist and the technician or other pharmacy staff. As a professional, pharmacist should not be much involved in the duties that are not their domain. Therefore, it was an interesting fact showed by this paper that the community pharmacist in Indonesia would also like to allocate their time on doing duties that are not related to their profession.

A reasonable thesis to explain this phenomenon is that the Indonesian community pharmacists were lacking of competence in delivering pharmaceutical services. Competencies might be reflected in their ability to maintain their professional practice, yet this paper showed the fact that the respondents were hardly difficult just to provide some professional work which are part of pharmacist competencies. Interesting remark from Maitreemit ${ }^{23}$ concluded that to meet the expected competencies in professional practice, pharmacists are depending on pharmacyrelated organizations and schools of pharmacy to response the change on pharmacist role. Both institutions are expected to adjust their role and the educational system to meet the current standard of pharmacist competencies. In addition, collaborative working of each other is the main key to enhance the required competencies.

These conflicts of works if it is not swiftly resolved may evolve to a bigger problem on pharmacist professional image. Rasool ${ }^{24}$ reported that deficiencies in pharmacist professional practice may result a poor perception of patients and physicians on pharmacist image. Patient adherence will be reduced when pharmacist fails to fulfill the patients' expectations and they will think that pharmacist is incapable to provide a professional service regarding their medications, treatments or any possible side effects of drugs. Physicians will also perceive pharmacist is not knowledgeable about the medications when pharmacists does not interact and give more time to discuss the dosage, frequency of usage and the other information needed to provide a rational prescribing to the physicians. Thus, in the end Rasool emphasized that pharmacist should provide more time and more space to interact with the patients and physicians.

Overall, the findings on this paper strengthened the other studies ${ }^{25-28}$ that most of community pharmacists in developing countries, particularly in Asian countries, are still in conflict with non professional work, while pharmacists in developed countries enjoy a settled position as healthcare professionals. ${ }^{29-31}$ For comparison, Azhar ${ }^{32}$ found that Community Pharmacists in Pakistan were also concerned about their professional role in the healthcare system. This because pharmacists were more focused on the management and business context instead of customer services. As the consequence, pharmacist role is not familiar to the public. Similar experience also occurred in Palestine, Vietnam, Laos and India where community pharmacy operations were more business oriented than health services oriented ${ }^{33,34}$. An interesting comparative study carried out by Parmar ${ }^{35}$ when she compared pharmacy practice in Kenya and United States. She concluded that community pharmacist in the United States were more patient oriented while in Kenya, they were more economically driven.

This paper also implied that pharmacy technician or other pharmacy staff might have the opportunity to substitute the role of pharmacist in the pharmacy because the pharmacist absence. This assumption is in line with the fact in Pakistan where pharmacist's role was being taken over by the nonprofessionally qualified personnel working in community pharmacies as dispenser of medicine due to pharmacist shortage. ${ }^{36}$ This means if pharmacists do not exist in the pharmacy, another actor would have more time and more desire to undertake the pharmacist's duty. Therefore, this paper assumed that this is also the factors that may de-professionalize the profession; indeed it threats the pharmacy profession.

A strategic change must be undertaken to prevent the state of de-professionalization in Indonesia by improving the existence of pharmacists so they can interact better with the patients, otherwise the pharmacy profession will experience "commodification" because the services will only be valued from the commodity given to the patient.

However, caution should be applied before generalizing the result to all community pharmacists in Indonesia since the low response rate of this research may create a bias conclusion. Therefore, 
the researchers suggested that the results might only be fitted to the pharmacists in Surabaya. In another words, this overview was limited to community pharmacy practice in Surabaya.

Another pitfall that may be considered before referencing the result of this research was the parameter of the evaluation which was based on the qualitative measurement. This means the differences between one, two or even five scales in the Likert Scale was based on the assumption of the respondents to classify their amount of time. This research did not use the quantitative measurement in work hours due to problems of quantifying time because in reality professional and non professional work was sometime overlapped and mixed up each other, so it would be difficult to distinct the amount of work hours. Using quantitative measurement would also create a bias since the respondents may plausibly declare the amount of time that they really spent in the pharmacy. Therefore, the purpose of this research was not trying to quantify the time but it was trying to find the expectation and the gaps with the fact.

\section{CONCLUSIONS}

The Indonesian community pharmacists were spending little time on both professional works and non-professional works in their daily activities. However, they desired to spend more time on providing both types of work in the ideal situation. This indicated that pharmacists did not focus on delivering quality professional works and they still interrupted by some nonprofessional aspects. This might erode professionalism of pharmacists and potentially de-professionalize the profession. A strategic change must be undertaken to prevent this state of de-professionalization by exposing pharmacists to the patients frequently.

\section{CONFLICT OF INTEREST}

None declared.

\section{References}

1. Hibbert D, Bissell P, Ward RP. Consumerism and professional work in the community pharmacy. Sociol Health IIIn. 2002:24(1):46-65.

2. Rouse MJ. Continuing professional development in pharmacy. Am J Health Syst Pharm. 2004;61(19):2069-2076.

3. Cooksey JA, Knapp KK, Walton SM, Cultice JM. Challenges to the Pharmacist Profession from Escalating Pharmaceutical Demand. Health Aff (Millwood). 2002;21(5):182-188.

4. Freidson E. Professionalism, the third logic: on the Practice of Knowledge. Chicago: University of Chicago Press; 2001. ISBN: 978-0226262031

5. Traulsen JM. Bissel P. Theories of professions and the pharmacist. Int J Pharm Pract. 2004:12:107-114.

6. Wiedenmayer K, Summers RS, Mackie CA, Gous AS, Everard M, Tromp D. Developing Pharmacy Practice, A focus on Patient Care. The Hague: WHO-FIP; 2006.

7. Cordina M, Safta V, Ciobanu A, Sautenkova N. An assessment of community pharmacists' attitudes towards professional practice in the Republic of Moldova. Pharm Pract (Internet). 2008:6(1):1-8.

8. Denzin NK, Mettlin CJ. Incomplete Professionalization: The Case of Pharmacy. Social Forces. 1968:46:375-381.

9. Krishnaprasad SS. Measuring Perception of Health Care as a Commodity or as a Public Right among Community Pharmacist in Saskatchewan. Saskatoon: University of Saskatchewan. 2008.

10. Perepelkin JP. Relating Ownership Type to the Organizational Behaviour, Role Orientation and Autonomy of Community Pharmacy Managers in Canada. Saskatoon: University of Saskatchewan. 2008.

11. Anderson RD. The Peril of Deprofessionalization. Am J Health-Syst Pharm. 2004:61(22):2373-2379.

12. Anderson S. The State of the World's Pharmacy: A Portrait of the Pharmacy Profession. J Interprof Care. 2002:16(4):391-404

13. van Mil JW, Frokjaer B, Tromp TF. Changing a Profession, Influencing Community Pharmacy. Pharm World Sci. 2004;26(3):129-132.

14. Zelmer WA. Unresolved Issue in Pharmacy. Am J Health-Syst Pharm. 2005:62:259-265.

15. van Mil JW, Schulz M. A Review of Pharmaceutical Care in Community Pharmacy in Europe. Harvard Health Policy Review. 2006;7:155-168.

16. Morgall JM, Almarsdóttir AB. No Struggle, No Strength: How Pharmacist Lost Their Monopoly. Soc Sci Med. 1999;48(9):1247-1258.

17. Norris PT. Challenges facing Social Pharmacy. Res Social Adm Pharm. 2009;5(3):195-196

18. Statistical Bureau of Surabaya. Surabaya in Figures: 2008. Statistical Bureau of Surabaya. 2009.

19. Rutter PM, Duncan G. Can professionalism be measured?: evidence from the pharmacy literature. Pharmacy Practice (Internet). 2010:8(1):18-28.

20. Dingwall R, Wilson E. Is pharmacy really an incomplete profession? Perspect Soc Problems. 1995:7:111-128.

21. Smith F. The Quality of Pharmacy Services in Low and Middle Income Countries: A Systematic Review. Pharm World Sci. 2009;31(3):351-61.

22. Smith F. Community Pharmacy in Ghana: enhancing the contribution to primary health care. Health Policy Plan. 2004;19(4):234-41.

23. Maitreemit $P$, Pongcharoensuk $P$, Kapol N, Armstrong EP. Pharmacist Perceptions of New Competency Standards. Pharm Pract (Internet). 2008:6(3):113-120. 
24. Abdul Rasool BK, Fahmy SA, Abu-Gharbieh EF, Ali HS. Professional practices and perception towards rational use of medicines according to WHO methodology in United Arab Emirates. Pharm Pract (Internet). 2010:8(1):70-76.

25. Azhar S, Hassali MA, Ibrahim MI, Ahmad M, Masood I, Shafie AA. The Role of Pharmacists in developing countries: The Current Scenario in Pakistan. Hum Resour Health. 2009;7:54.

26. Basak SC, van Mil JW, Sathyanarayana D. The Changing Roles of Pharmacists in Community Pharmacies: Perception of Reality in India. Pharm World Sci. 2009;31(6):612-618.

27. Chuc NT, Larsson M, Do NT, Diwan VK, Tomson GB, Falkenberg T. Improving Pharmacy Practice : A Multi Intervention Experiment in Hanoi, Vietnam. J Clin Epidemiol. 2002;55(11):1148-1155.

28. Stenson B, Syhakhang L, Eriksson B, Tomson G. Real World Pharmacy: Assessing the Quality of Private Pharmacy Practice on the Lao People's Democratic Republic. Soc Sci Med. 2001;52(3):393-404.

29. Adu A, Simpson J, Armour C. Pharmacists' and physicians' perception of antibiotic policies in New South Wales public hospitals. Int J Pharm Pract. 2001:9(1):31-36.

30. Bond C, Matheson C, Williams S, Williams P, Donnan P. Repeat Prescribing: A role for community Pharmacists in Controlling and Monitoring Repeat Prescriptions. Br J Gen Pract. 2000;50(453):271-275.

31. Schommer JC, Pedersen CA, Gaither CA, Doucette WR, Kreling DH, Mott DA. Pharmacists' Desired and Actual Times in Work Activities: Evidence of Gaps from the 2004 National Pharmacist Workforce Study. J Am Pharm Assoc. 2006;46(3):340-347.

32. Azhar S, Hassali MA, Ibrahim MI, Ahmad M, Masood I, Shafie AA. The role of pharmacist in developing countries: the current scenario in Pakistan. Hum Resour Health. 2009;7:54.

33. Jaradat N, Sweileh W. A Descriptive Study of Community Pharmacy Practice in Palestine: Analysis and Future Look. An-Najah University Journal for Research. 2003:17(2):191-199.

34. Attewell J, Blenkinsopp A, Black P. Community pharmacists and continuing professional development - a qualitative study of perceptions and current involvement. Pharm J. 2005:274:519-524.

35. Parmar S. Community Pharmacy Practice in the United States and Kenya: Comparison. Diabetes in Control.com. 2008:408. URL: http://www.diabetesincontrol.com/articles/54-feature/5614-. Posted 18 March 2008. (Accessed 15 December 2011).

36. Hussain A, Ibrahim MIM. Perceptions of Dispensers regarding dispensing practices in Pakistan: A Qualitative Study. Tropical Journal of Pharmaceutical Research. 2011;10(2):117-123. 